\title{
JUAN ALONSO DE VILLABRILLE Y RON, MAESTRO DE LUIS SALVADOR CARMONA
}

Hasta la fecha, conocemos pocas noticias referentes a la vida y obra del importante escultor Juan Alonso de Villabrille y Ron. La escasez de documentación histórica encontrada y las pocas esculturas atribuibles con seguridad al maestro asturiano han hecho que, de momento, no se pueda perfilar con precisión, la formación artística de Villabrille, sus prácticas escultóricas en Madrid, o el papel que desempeñó como instructor de jóvenes aprendices ${ }^{1}$ Sobre este último aspecto y sobre otros de su vida cotidiana, en las próximas líneas, damos a conocer algunos datos nuevos, entre ellos un documento importante: la obligación de aprendizaje contraída entre Juan Alonso de Villabrille Ron y Luis Salvador Carmona.

Juan Alonso de Villabrille y Ron debió nacer hacia 1633. Sabemos, gracias a una declaración de probanza de hidalguía, que era natural de Algur, parroquia de Pesoz (Asturias) y que sus padres se llamaban Juan Alonso de Villabrille y María López Villamil ${ }^{2}$. En 1686 está instalado en Madrid viviendo en la parroquia de San Ginés y, al año siguiente, entra en su taller un joven, Jerónimo Soto, para aprender el oficio de escultor ${ }^{3}$. Villabrille, «residente en esta Corte y vecino desta dicha Villa de Madrid», da poder, en 1689, a don Fernando de San Pedro, vecino de Sampayo (Asturias), para oponerse a la ejecución que tenían pedida, Pedro López de Villabrille y Alonso López de Vilabrille, contra los bienes y hacienda de sus padres ${ }^{4}$ En 1708 es nombrado con su esposa heredero universal de los bienes de D. Pedro Roco, presbítero capellán del convento de las Madres Mercedarias Calzadas de Madrid, que era el tío de su primera mujer D. ${ }^{a}$ Teresa García de Muñatones ${ }^{5}$. Además, en el mismo año, D. Antonio Reco otorga poder en favor de D. Juan Ron para que cobre la herencia de D. ${ }^{a}$ Antonia Ramírez «viuda que fue de Pedro de Soto, mozo del ofizio de la fruteria de la reyna $\mathrm{N}^{\mathrm{a}} \mathrm{S}^{\mathrm{a}}{ }_{\gg}{ }^{6}$.

En 1710, el escultor D. José Galbán, natural de Segovia y vecino de Madrid, toma por esposa a D. ${ }^{a}$ Andrea de Villabrille y Ron, hija de D. Juan y de D. ${ }^{a}$ Teresa ${ }^{7}$. La dote que D. ${ }^{a}$ Andrea aporta a su matrimonio asciende a 24.111 reales de vellón, cantidad nada despreciable, que corresponde al valor de diversos bienes, entre ellos: dos pinturas de Palomino (N. ${ }^{a} S .^{a}$ de la Concepción y S. Francisco Javier en oración), una de Vicente Carducho (La familia de San Francisco), otra de Eugenio Cajés (Martirio de S. Esteban) y, finalmente un lienzo del Labrador

\footnotetext{
${ }^{1}$ A este respecto véanse los artículos: Marcos Vallaure, E., «Juan alonso de Villabrille y Ron, escultor asturiano», Boletín del Seminario de Arte y Arqueología de Valladolid, año 1970, págs. 147-57; Marcos Villaure, E. «Juan Alonso de Villabrille y Ron o Juan Ron», Boletín del Seminario de Estudios de Arte y Arqueología de Valladolid, año 1975, págs. 403-144.

${ }^{2}$ Marcos Vallaure, «Obra cit.», B.S.A.A., 1975, págs. 403-404.

${ }^{3}$ A.H.P. 10.360 folio 35 recto y vuelta. Tomado de Agulló y Cobo, M., Documentos sobre escultores, entalladores y ensambladores de los siglos XVI, XVII y XVIII, Valladolid, 1978, págs. 170-171.

${ }^{4}$ A.H.P. 10.177, folios 532-533. Tomado de Agulló, M., Obra cit., Valladolid, 1978, págs. 170-171.

5 A.H.P. 14.352 sin foliar. 3 de mayo de 1708. Dos años más tarde, en 1710, aparece Villabrille con su futuro yerno Juan Galbán como testigos en un documento referente a Roco. A.H.P. 14.352, folios 376-378. El 12 de octubre de 1712, Juan Ron cobra 3.810 reales de vellón «por los réditos de tres años a raçon» de 1260 reales en cada uno por un censo, de 3.500 ducados de principal, impuesto sobre unas casas. Estas rentas las recibe el escultor como heredero del presbítero Roco. A.H.P. 14.353 , folio 320 recto y vuelta.

${ }^{6}$ A.H.P. 14.352, folio 74 recto y vuelta. Obsérvese, que el Pedro de Soto, al que se refiere el documento, puede ser pariente de Jerónimo de Soto, el joven aprendiz que entró en el taller del escultor en 1687.

${ }^{7}$ Noticia tomada del Marqués del Saltillo, «Efemérides artísticas madrileñas (1603-1811)», Boletín de la Sociedad Española de Excursiones, LII, 1948, págs. 40-41. A.H.P. 14.352, folios 340-343v. D. Emilio Marcos Vallaure hace también referencia a este documento en: «Obra cit.», B.S.A.A., 1975, págs. 404-405.
} 
de cuatro racimos de uvas ${ }^{8}$. Todo ello nos autoriza a intuir, de una aparte, un cierto gusto de Villabrille a la hora de elegir la pintura que compraba, ya que poseía obras de maestros de su época y de los más famosos de los reinados de Felipe III y Felipe IV. Además y de otra parte, una desahogada posición económica, que le permitía tener casas en propiedad, como ahora demostraremos, y que vendría fortalecida por ingresos extraordinarios, como los ya apuntados en relación con D. Pedro Roco.

Los Villabrille debieron vivir en unas «casas propias» de la calle de San Antón de Madrid, pues así se declara en la carta de dote arriba citada y más tarde en una tasación, de las esculturas del Vizconde de la Frontera, que hace Juan Ron en $1711^{9}$. Su mujer, D. ${ }^{a}$ Teresa, debió sentirse mal de salud en marzo de 1712, pues el día 20 de aquel mes otorga poder para testar a su marido ${ }^{10}$. En octubre de aquel año había desaparecido ${ }^{11}$. A su vez, sabemos, por el testamento de Juan Ron, otorgado el 28 de octubre de 1728, que nuestro escultor tuvo un segunda mujer, Jerónima Gómez, y tres hijos Juan, Andrea y Tomás, este último religioso de la Compañía de Jesús ${ }^{12}$.

Ceán Bermúdez, en su Diccionario, al referirse a Juan Ron ${ }^{13}$, nos dice que éste fue «maestro de su yerno D. José Galván y de D. Luis Salvador Carmona, los que le ayudaron en sus principales obras» ${ }^{14}$. Ceán puntualiza de nuevo el dato, sobre la formación de Luis Salvador en el taller de Villabrille, al narrar la vida y obra del famoso vallisoletano. La noticia ha sido aceptada como válida por los historiadores que se han dedicado al estudio de ambos escultores aunque, nadie, hasta hoy, había confirmado documentalmente el hecho. Esta circunstacia, no nos permitía, por un lado, fijar con seguridad la fecha de encuentro de ambos maestros y, por otro, la edad del joven Luis en aquel momento, significativa para determinar la pronta colaboración con Villabrille en encargos de importancia. Además, tampoco había sido posible esclarecer las claves de la venida de Carmona a Madrid: ¿Quién le acogió y ayudó en su llegada a la Corte?

Luis Salvador Carmona había nacido en la Nava del Rey, provincia de Valladolid, el 15 de noviembre de $1708^{15}$. Dice Ceán que desde sus primeros años se mostró inclinado por las bellas artes, «recortando estampas y haciendo figuras con navaja; y siendo muchacho ejecutó un crucifijo de madera sin otra dirección ni maestro que su ingenio lo que movió a un canónigo de Segovia que lo había visto, a enviarle a Madrid a la enseñanza de D. Juan Ron» ${ }^{16}$. La llegada a la Corte debió producirse, probablemente, a principios del mes de junio de 1723, ya que Juan Alonso de Villabrille y Ron en la obligación de aprendizaje, según escritura otorgada el 24 de octubre de 1723 ante el escribano Juan José de Ugarte, documento que por primera vez se da a conocer, declara que Luis Salvador Carmona había entrado en su taller como aprendiz el día de

\footnotetext{
${ }^{8}$ Esta obra «de más de media bara en cuadro» se corresponde en sus medidas, asunto y maestro, con otra análoga de la actual colección Naseiro.

9 A.H.P. 14.353, 18 de mayo de 1711, sin foliar. El vizconde tenía también una interesante colección de pinturas con obras originales de Rubens, Ribera, Bartolomé Pérez, entre otros maestros, cuyo estudio es parte integrante de nuestra tesis doctoral, «El coleccionismo privado de pinturas en España en los siglos XVII y XVIII», que, en la actualidad, estamos concluyendo.

10 Marqués del Saltillo, «Obra cit.», B.S.E.Ex., 1948, págs. 40-41.

$"$ A.H.P. 14. 353. 12 de octubre de 1712. Así se declara en el citado cobro, de 3.812 reales de vellón correspondientes de la herencia de don Pedro Roco, por parte de Villabrille.

12 Agulló y Cobo, M., Obra cit., Valladolid, 1978, págs. 170-171. A.H.P. 16. 295, sin foliar.

13 Don Emilio Marcos Vallaure ha demostrado que el escultor Juan Antonio Ron o Juan Ron que menciona Ceán, en su Diccionario, equivale a la persona de Juan Alonso de Villabrille y Ron. Véase a este respecto: Marcos Vallaure, E., «Obra cit.», B.S.A.A., año 1975, págs. 403-414.

${ }^{14}$ Ceán Bermúdez, J. A., Diccionario histórico de los más ilustres profesores de las Bellas Artes en España. Real Academia de Bellas Artes de San Fernando. Madrid, 1800, tomo IV, págs. 249-250.

${ }_{15}$ Carbonero, F. Biografía de Luis Salvador Carmona notable escultor castellano del siglo XVIII, Valladolid, 1901, 15 páginas.

${ }^{16}$ Ceán Bermúdez, J. A., Obra citada, Madrid, 1980, tomo IV, pág. 309.
} 
«San Juan de junio pasado» ${ }^{17}$ del año de 1723 . A este repespecto, las condiciones de la obligación de aprendizaje son las habituales en la sociedad española del siglo XVII y XVIII por las cuales: «Juan Alonso de Villabrille y Ron vezino deste dicha Villa y Maestro escutor», recibe a Luis Salvador, «para que le enseñe el mismo arte y profesión». Y en este tiempo, el joven aprendiz, «no se yra ni ausentara dellea (Madrid) y si lo hiziere el otorgante y el padre del susodicho solizitarian y aran diligencias nezesarias en su busca... y D. Juan de Alonso de Billa brille le a dedar de comer ropa limpia lonezesario; $\mathrm{Y}$ el dicho su padre y otorgante en su nombre de vestir calzar y ropa blanca que hubiere menester...» ${ }^{18}$.

En la citada escritura se indica que el escultor contaba la edad de 15 años y que era hijo de Luis Salvador, vecino de la villa de la Nava del Rey. Como es lógico, la minoría de edad de Carmona no le permitía adquirir ningún tipo de obligación legal por cuenta propia, además la pobreza de su familia ${ }^{19}$ imposibilitó, seguramente, el que su progenitor le acompañara a Madrid, ya que en la obligación de aprendizaje, que estamos estudiando, es Diego Martínez de Arce quien actúa en nombre de Luis Salvador padre, como tutor y responsable del joven escultor.

Martínez, natural de Medina del Campo, residía entonces en la Corte y era discípulo del arquitecto Miguel de Yrazusta ${ }^{20}$. Según el profesor Jesús Urrea, Martínez de Arce se había formado en el taller de su padre Francisco, el cual no solamente había realizado trabajos para Medina del Campo, sino también algunas obras destinadas a Nava del Rey, en donde posiblemente conocería a Luis Salvador padre, que debía ser un artesano relacionado con la ebanistería. El hecho de que Diego fuera el responsable de Luis en Marid, de que se obligara, según el documento que publicamos, a «darle de vestir, calzar y ropa blanca» por el tiempo que durara el aprendizaje con Villabrille, nos da pie a corroborar, lo intuido por el Sr. Urrea, de que la amistad de ambos jóvenes había nacido ya en tierras vallisoletanas, como consecuencia de la relación de sus padres ${ }^{21}$.

Nos parece legítimo pensar que si Martínez de Arce puso a Salvador Carmona en contacto con Villabrille, también pudo haberle presentado a su maestro Yrazusta. Esta circunstancia permite reforzar la teoría ya apuntada ${ }^{22}$, de que una vez desaparecido Juan Ron y en los años que transcurren desde 1730-1739, los peor documentados por lo que respeta a las actividades escultóricas de Carmona, nuestro artista no solamente se asociara al escultor José Galbán, tal y como nos informa Ceán ${ }^{23}$, sino que también tuviera una estrecha relación laboral con su amigo Diego y con el arquitecto Miguel de Yrazusta que necesitaba escultores para la decoración de sus portadas y retablos ${ }^{24}$.

${ }^{17}$ A.H.P. 14.659 , folio 720 recto y vuelta.

${ }^{18}$ Idem.

19 Urrea, Jesús, «Revisión de la vida y obra de Luis Salvador Carmona», Boletín del Seminario de Estudios de Arte y Arqueología de Valladolid, año 1983, págs. 449-450.

${ }^{20}$ Urrea, Jesús, «Obra cit.», B.S.A.A., 1983, pág. 444.

${ }^{21}$ En este sentido, parece que la relación de Luis Salvador Carmona con el ambiente de Medina del Campo tuvo que ser muy cercana, ya que su primera mujer, Custodia Hernández de Paredes, era natural de Medina del Campo, al igual que su suegro y su madre. Véase al respecto: García Gaínza, M. ${ }^{a}$ Concepción, Obra cit., Navarra, 1990, pág. 12.

${ }^{22}$ Urrea, Jesús, «Obra cit.», B.S.A.A., 1983, pág. 444.

${ }^{23}$ Ceán Bermúdez, Obra citada, Madrid, 1800, p’g. 310.

${ }^{24}$ En este sentido, se debe recordar que García Gaínza demostró la colaboración de Yrazusta y Carmona en el retablo

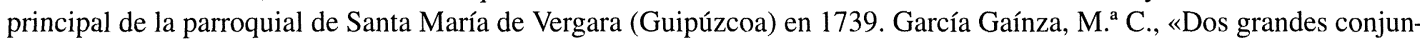
tos del barroco en guipúzcoa. Nuevas obras de Luis Salvador Carmona», Revista de la Universidad Complutense, 1973, págs. 81-110. Además, Martínez de Arce, una vez desaparecido Yrazusta, siguió asociado con Carmona y ambos colaboraron en los retablos mayores de las parroquiales de Segura (Guipúzcoa) y de los Yébenes (Toledo). Véase García Gaínza, M. C., «Obra cit.», Revista de la Universidad Complutense, 1973, págs. 81-110 y Urrea, J., «Obra cit.», B.S.A.A., 1983, pág. 445. 
Dicho esto y volviendo a la obligación de aprendizaje que otorgan Diego Martínez, como tutor de Luis Salvador, y el escultor Juan de Villabrille y Ron, es curioso señalar que ésta se hizo pública, ante el citado escribano, cuatro meses después de que el joven Carmona entrara de hecho en el taller del asturiano. A este respecto, el texto dice lo siguiente: «En la villa de Madrid a beintycuatro dias del octubre año de mill setezientos y veinte y tres... Parezio Diego Martinez residente en ella por la presente pone por aprendiz a Luis Salbador de hedad dequinze años hijo de Luis Salbador vezino de la villa de la Nava del Rey, encasa y poder de Don Juan Alonso de Villabrille y Ron vezino de esta dicha villa y maestro escultor para que le enseñe el mismo arte y profesion por tiempo de seis años que tubieron prinzipio y que se quentan desde el dia de San Juan de junio pasado» ${ }^{25}$. Llama la atención el carácter retroactivo del contrato, que no se había dado en la otra escritura de aprendizaje con el joven Jerónimo Soto ${ }^{26}$, y que podría indicar una desconfianza inicial de Villabrille sobre el joven vallisoletano al que concedería un periodo de prueba, de cuatro meses, para que demostrara sus aptitudes e interés.

La duración del aprendizaje se estipuló en seis años, es decir desde el 24 de junio de 1723 hasta el 24 de junio de 1729. Durante estas fechas, como es bien conocido se instalaron las esculturas de San Isidro y Santa María de la Cabeza en el puente de Toledo (1723), y la de San Fernando en la fachada del Hospicio (1726). Se debe recordar al respecto, que tanto en el Diccionario de Ceán como en el conocido Memorial del escultor ${ }^{27}$, se indica que Luis Salvador intervino en las tres obras en forma directa y bajo la dirección de Villabrille. Circunstancia que pone de manifiesto la precoz genialidad del vallisoletano, pues con tan solo 15 años ya colaboraba en obras de capital importancia a las órdenes de Juan Ron, su maestro.

Salvador SALORT PONS

Becario de Investigación de la Universidad Complutense

Archivo Histórico de Protocolos. Protocolo Número: 14659, folio 720 recto y vuelta

Obligazion de aprendiz otorgada

entre Diego Martinez y Juan

En 24 de Octubre de 1723

Alonso de Villabrille y Ron

En la villa de Madrid a beinteyquatro días del mes de octubre año de mill setezientos y veinte y tres antemi el ss.no y testigos parezio Diego Martinez de Arze residente en ella Porlapresente pone por aprendiz a Luis Salbador de hedad dequinze años hijo de Luis Salbador vezino dela Villa dela Nava del Rey, encasa y poder de Dn. Juan Alonso Villabrille y Ron vezino deesta dicha Villa y Maestro escultor para que leenseñe el mismo arte y profesión portiempo de seis años que tubieron prinzipio y sequentan desde el dia de San Juan de Junio pasado deeste de la dicha a lo qual seobliga aque asistiera en casa del susodicho Ynose yra ni ausentara deella y si lo hiziere el otorgante y el padre del susodicho solizitarian y aran diligenzias necesarias ensubusca y volbera aella y las faltas que hizie-

\footnotetext{
${ }^{25}$ A.H.P. 14.659 , folio 720 recto.

25 A.H.P. 10.360, folio 35 recto y vuelta. Tomado de Agulló y Cobo, M., Obra cit., Valladolid, 1978. En esta escritura, fechada el 8 de abril de 1687, se declara que el joven Soto había entrado en el taller de Juan Ron el día uno de abril de aquel año. Es decir, solamente había pasado una semana, desde la incorporación al taller, hasta que se hizo escritura pública de la obligación de aprendizaje contraída.

${ }^{27}$ Moreno Villa, J., «Memorial del escultor don Luis Salvador Carmona», A.E.A., vol. VIII, págs. 98-99. El texto dice: ...«y también travajó en el San Fernando q. adornan el pórtico de la fundación Real de el Ospicio y en los santos de la Puente de Toledo».
} 
re la a de cumplir despues de dichos seis años Porcada dia dos, encuio tiempo leadedar el dicho Dn. Juan Alonso Billa brille de comer cama ropa limpia lonezesario; $\mathrm{Y}$ el dicho su padre y otorgante en su nombre de vestir calzar y ropa blanca que hubiere menester durante el dicho tiempo: Y el dicho Dn. Juan Alonso de Villa a vrille que stalla presente dijo le tiene rezvido y le tiene por tal suaprendiz al dicho Luis Salbador menor y seobliga atenerle los dichos seis anos que empezaron a correr desde el referido dia de San Juan de Junio pasado deeste del afecha ensucasa y en el discursos deellos enseñarle el dicho ofizio y arte de escultor y darle abil y sufiziente para que pueda trabajar por ofizial y comotal gane el estipendio que escostumbre entre los de dicho ejerzizio y encaso de no estar abil se lodara el dicho otorgante hasta que se abilite y lo pueda ejecutar enotra qualquiera parte y tambien a darle de comer cama y ropa limpia lonezesario y leara curar las enfermedades que tubiere como no exzedan de Quinze dias nisean causadas demano o mal bizio que tome dicho suaprendiz y en la forma que qeda espresada cada uno de los otorgantes por lo que les toca y puede tocar seobligan consus personas y bienes muebles y raices avidos y por haber y dan poder alas justizias desu Mag. De quales queserpartes que sean y en expezial alos señores alcaldes de esta corte Corregidor y Tenientes deesta Villa de Madrid acuio fuero y jurisdizion y decada una ynsolidum sesometen para que les apremien alo obienrear Y cumplir comoporsentenzia pasada encosa Jargada que portal lo reziven y renunzian supropio fuero jurisdzion y domizilio y laley sit combene set deJuirisdizione omnium yudecum y de todas las demas leyes fueros y otros de su favor conla que prohive la general renunziazion detodas en forma yassi lo otorgaron y firmaron aquienes yo el escribano doy fe conozco siendo testigos Andres de la Viuda Francisco Sanz y Miguel Sazeda del Castillo residentes en esta Corte.

Juan Alonso de Villa Abrille y Ron

Diego Martínez de Arze

Antemi

Juan Joseph de Ugarte 